\title{
The Way We Live Now
}

\section{Casualties}

\author{
TONY DELAMOTHE
}

If during her Dulwich retirement Mrs Thatcher were suddenly taken ill this is where the ambulance would bring her. Not to the private room with en suite bathroom, telephone, television, and doctor of her choice. But here. If she were really ill with one of the many conditions that does not interest the private sector Martin and Mark (or Joe and Mick, or Sandra and Chris) would skirt round the edge of the sixth most deprived borough in the country, turn left at the sign "kindly donated by the Friends of King's College Hospital," and left again into the hospital grounds, their blue light flashing. They would wheel her through the swing doors, transfer her from ambulance stretcher to hospital trolley in the corridor, and wheel her into emergency. Doctors and nurses would already be there, waiting for her. Looking up, their patient could make out the true ceiling through the gaps where the false ceiling has fallen away. High up at the corners of the room she could see the spotlights that run off the hospital's emergency power supply. (Meant for power cuts, they are hand held during emergency surgery now because the false ceiling is too weak to support proper lighting.) And if it were summer and she looked out through the open windows-it's against the rules to open them, but the room gets unbearably hot with them closed-she might find herself the subject of considerable interest to passengers on the top of passing buses.

I am sitting in the accident and emergency department of King's College Hospital trying to read the signs. Starting on my left I am told (in eight languages) not to spit. Next there is a sticker on the door I came through reminding me it's guide dogs only. Between the door and the triage desk signs request me to give blood before I go on holiday, find my own way to hospital, watch my drinking, and Stop and Think. One sign thanks me for not smoking; others just show a cigarette with a line through it. Above the triage desk I am exhorted to keep flu to myself and given a few simple facts about asthma, although in type too small to read from where I am sitting. And then I am reminded of four things that won't give me AIDS. That's $180^{\circ}$. Behind me a white screen about eight feet high separates the waiting area from the cubicles. Directly overhead there is a large skylight with dirty green blinds and just below a television set. Recently installed, it has had a notably calming effect, although tempers flare when casualty officers want to turn down the volume to listen to somebody's heart.

It's just after 9 am and patients being seen now by casualty officers arrived an hour ago. A patient who arrived at 6 am has been found a bed on the ward. The television programme changes from Neighbours to Kilroy, today's topic "Unemployment-excuse for the workshy?" The studio audience is articulate and well dressed, its seating arrangement identical with ours out here. If you half closed your eyes you could believe the television screen to be a magic mirror, in which everyone on this side could see themselves reflected whole. They discuss whether it is right that people should have to come down south for work. A member of parliament is extolling the virtues of a deregulated economy. And as she does, the first of the day's work injuries hobbles to the door marked "Please come this way when your name is called." Before the programme is over the dressing room is full of men clutching white pads to bleeding hands, occupational injuries all, deregulation's martyrs. Their stigmata drench the white bandages, and the blood flows down their arms over the white basin and on to the floor. Nurses rather than domestic staff clean up vomit and blood. ("And if you don't get it while it's wet it's twice as hard to clean up afterwards, and if anybody slips over then it's you who answers for it.") A man arrives who has fallen off a ladder. He limps over to the triage desk, holding his side, becoming paler and paler. At first he resists any suggestions to lie down-he doesn't want to be any trouble. I think he is bleeding from somewhere. Nobody forces him to do anything he doesn't want to do, but they have a trolley ready for when he crumples on to the desk. (He goes home later that day, his diagnosis recorded laconically as \#.)

Two young men enter wearing suits and smiles and carrying briefcases: they look as if they have walked straight off Kilroy. They represent a biomedical company and have arrived uninvited to promote a product that the accident and emergency department does not (and probably will never) stock. A student nurse deals with them politely but firmly and suggests that they should write first. A few hours later a similar visitor arrives on similar business. (Do they clone them?) I meet him swearing to himself in the corridor, off in search of some consultant's secretary or the mess president.

The procession of mothers and babies has begun. Unlike the reps they know how to get seen. Through the swing doors and hard left to reception. Give a few details or, better still, hand over the card they gave you yesterday or last week. Sit down for five or 10 minutes until

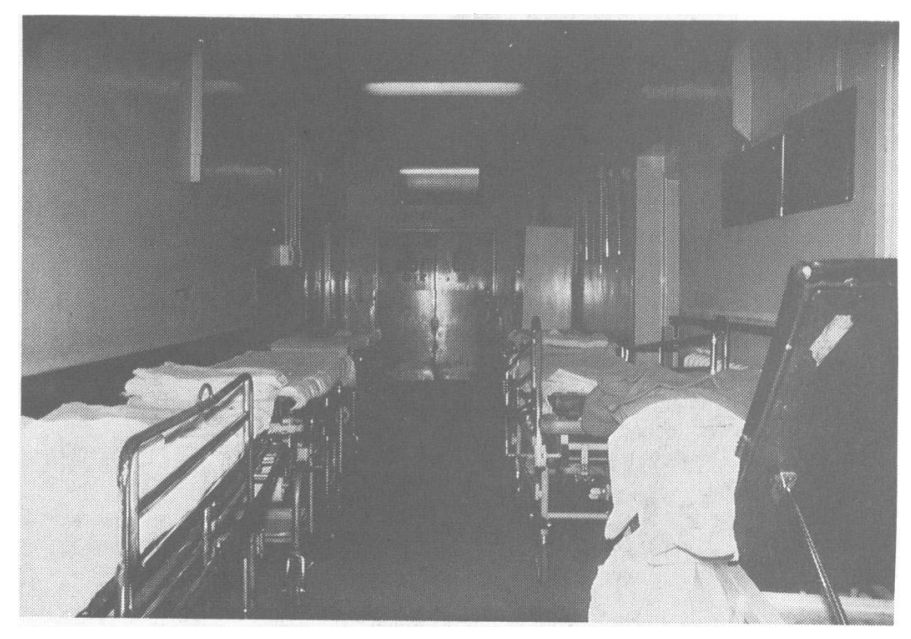

Space, like just about everything else, is at a premium at King's. Here trolleys crowd out one of the main corridors. 
sister or staff nurse calls you to the triage desk and greets you with a cheery "Hello, and what can we do for you?" Baby 1 was here yesterday, but the rash has got worse. She is sleepy but taking fluids. Her mother (mid to late teens, it is difficult to tell) chews anxiously on her baby's dummy. Baby 2 wolfs down her bottle and lunges out at her mother's cigarette packet.

Ambulances arrive with their first pick ups of the shift, mostly in wheelchairs. They wheel the patient straight to the triage desk, where they give a succinct account of the history and findings. One ambulanceman has a handwritten sticker on his tie that says "In Dispute." Quite a few ambulancemen have beards and earrings, although most ambulancewomen look caught in a time warp, dressed for a spot of wartime fire watching.

A man wanders from one cubicle to the next looking for something. When he finds it he spends 10 seconds looking at it closely. There is another 10 second inspection that afternoon. Nothing else happens on either visit. The son of the woman who had earlier asked me for $10 p$ pieces turns up with a portable telephone. This allows the woman's husband to make long, serious phone calls. Later somebody rings them. At exactly the same moment there's an electronic arpeggio from the television game show and somewhere in the distance a doctor's bleep goes off. The coincidence is as unlikely and unsettling as a triple eclipse.

$\star \quad \star \quad \star$

Now that he can walk unaided a man returns his crutches to the department as requested. He asks for a piece of paper as proof that he has brought them back. It is not just crutches that this stickler for detail leaves in the department. While waiting he cleans out his pockets, rolls the rubbish he finds there into a ball, and surreptitiously drops it on the floor.

Another patient after an accident at work. I cannot work out what he does or what has happened to him, but he is covered in dust. He leaves an imprint of himself on the chair at the triage desk. The woman who follows him there collects most of it on her Barbour jacket, although there are still traces of his presence hours afterwards. All the people who sit there take with them a little of his dust; the gift relationship: it is no longer blood we share but dirt.

By 1045 am the waiting area is empty. Out in the corridor a man with a bucket and some rags uses one of the two pay phones: "I've finished $x$ ray, the walls, and the ceiling. So $x$ ray is all clear. Have you heard about that job at Earl's Court yet? No, then I'll give them a ring." Here is today's new model businessman, two pounds something an hour, putting through a few morning calls. The corridors within a few yards of the pay phones are the best place to see the effects of this "casualisation of labour," whereby no one has more than a transient responsibility for anything. A haze of calligraphy is predictable around any pay phone, but here the walls groan with layers of filth. What looks like blood is smeared just above eye level. The ceiling doesn't help much-great chunks of plaster have fallen off and there are several large leaks and many smaller ones; their courses down the walls picked out in dust.

Returning to the waiting area at 11 am, I have missed a "red phone," a 1 year old with burns. I do not want to see what is going on, I can hear it well enough (the emergency area opens on to the waiting area). These screams are serious. On television the game show has changed to another chat show, this time on hunting. Those waiting seem more interested in the commercials for two sorts of dolls, named for their special features: Little Darling Bubbles and Little Darling Cries. Meanwhile, here in the department we are awash with examples of the real thing.

The same ambulance crews are back, this time with stretcher cases. No cubicles are available, so they park the patients around the edge of the waiting room, and the nurses start their observations there in full view of everyone. Many of this latest influx of patients, young and old, have female relations in tow. All distraught relations resemble each other, each patient is sick in his or her own way.

The baby with the rash is back from the $x$ ray department and is called in. Her mother shhhes her sleeping baby all the way to the door, but just as she enters the baby wakes up crying. Inside she sees

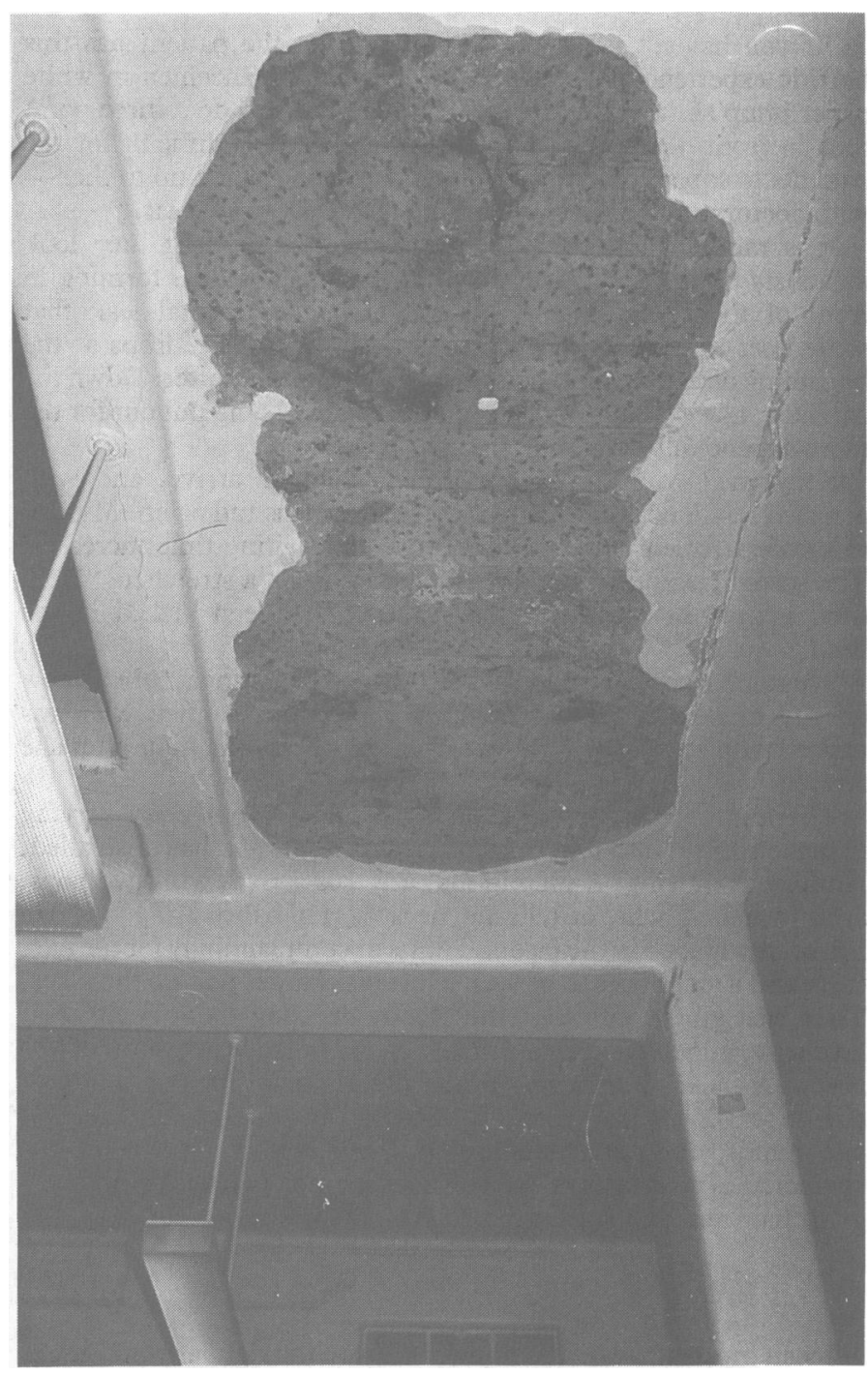

"Plaster is missing from the ceiling here and from the treatment room next door, where a length of green hospital towel has been twisted optimistically round a pipe to stop it leaking on to a trolley of syringes and needles."

one of three doctors in bays open above head height. Requests for curtains to provide more privacy here have been made four times (and their measurements taken three times), but so far nothing has happened. Plaster is missing from the ceiling here and from the treatment room next door, where a length of green hospital towel has been twisted optimistically round a pipe to stop it leaking on to a trolley of syringes and needles.

A woman who is obviously pregnant arrives at reception. The receptionist comes out, escorts her to a seat, and takes her casualty card to the triage nurse herself (usually they are collected by the nurses in batches every five or 10 minutes). This is fine. She will, however, have to be examined on a trolley; only six cubicles will take one and only two of these have doors. Both are full. The one in front of the waiting area is used not only for patients with obstetric and gynaecological problems but also for the infected, the infested, the intoxicated, and other patients who might be a danger to themselves or others ("because we can get all the furniture out pretty quick, except for this marble shelf'). At present it contains a very thin black man with diarrhoea and vomiting, who the ambulanceman thought might have AIDS. "Thank goodness he didn't make a song and dance about it, but just came and whispered it in my ear," says sister. Nevertheless, on the board behind the waiting area (and out of sight) there is ?HIV+ beside his name. He came into the department without problems, but how will he get out? 
"If you haven't got a sensible crew then the patient has this horrific experience of being collected by ambulancemen in white paper jump suits. Then they wheel them out and do a three point turn in front of the punters. It's awful. It's very difficult for the patients to square that with how they've been treated up to thenwith doctors and nurses going in and out in everyday gear."

It is raining, and as staff pass under the skylight they look anxiously up at it and then down at the small puddle forming in front of the triage desk. This is the temperamental leak that sometimes pours and sometimes lets through a few drops at the beginning of a storm and then stops. Today it is the latter. Down the corridor, however, the buckets and basins are being put out for the more dependable leaks.

Between 11 am and noon 21 new patients arrive, and with assorted relations and friends the department is full again. My end of the department smells of poverty. The waiting time increases. The second assault of the day is wheeled in on a stretcher. "He'll need neuro obs," someone calls out. "He's been kicked in the head."

This all happens in full view; the chance of getting a cubicle now on any pretext is slim, although the pregnant woman who was treated with such solicitude on arrival gets hers-an hour after she arrived.

There are three urgent rings on the telephone: somebody is trying to make an appointment for an outpatient clinic and has misdialled. Nothing is moving. A man in his early 20 s arrives with two boys, aged 11 and 14, who, he tells me, he is "sort of baby sitting for." He has been punched in the face and waits uncomplainingly for the next three and a half hours to be seen while his charges tear up the place. They visit all the cubicles, the bloody dressing room being their favourite; sit in the triage nurse's chair; borrow her copy of the British National Formulary, which diverts them for five minutes; and go for long walks around the hospital and out into the rain. No one minds; they are watching Falcon Crest. In it one of the characters is visiting his doctor, who wears an open neck shirt and a gold chain and has Van Gogh prints on the walls.

I visit the gents, which is immediately on the right as you come in through the main entrance. "Wet floor," proclaims the orange cone holding open its door: something of an understatement. What was originally plumbed into the first room is missing, although an earlier visitor has failed to notice. Inside the other one a lot of coughing and spitting is going on. It turns out to be the man ?HIV+. Maybe that ambulanceman was on to something. On the cistern the most prominent graffito, in thick gold felt tip, reads:

Me no dumb

Me no silly

Me we re condom

On my wille

Some pedant has corrected the "we re" in biro. I wander out along the wet road to get the urine off my shoes.

Back in the department an ambulance crew has wheeled in a woman who is not registered with a general practitioner and who speaks little English. Her husband does the talking. There are no cubicles and no trolleys, although she obviously needs both. In the mean time she is given just about the last chair available. One of its wheels judders uncontrollably, and there is what looks like an infected gash on its back cushion, which is otherwise covered by a light plaster wash. Along the seat cushion there is a row of cuts where nervous fingernails have dug in. The woman's husband objects to the delay and "threatens" to take her elsewhere. The nurses duck this one and make placatory noises: "We haven't got a cubicle. I'm just clearing a trolley, sir. I'm sorry." The man ?HIV+ is off to Dulwich hospital, sometime. His trolley is wheeled out of the cubicle. "Want to sit on a chair, love? We're just waiting for an ambulance for you."

After her two jugs of water in 15 minutes the pregnant woman is off to the ultrasound department in the very last chair. Its seat is inches rather than feet from the ground. It does not look comfortable even for someone not in an advanced stage of pregnancy. Patient and staff elect to see the funny side of this.

The waiting time increases. Everyone has adjusted his or her face to read, "I am not going to make a fuss, but I do want you to appreciate that I am suffering here, patiently." All except the husband of the woman who does not speak much English, who stands sentinel outside her cubicle, trying unsuccessfully to catch someone's eye. (She is eventually seen in turn, given an injection to ease her pain, and transferred to the ward. Nobody ever doubted the genuineness of her symptoms, but nor could they justify seeing her before other people who were just as ill.)

Casualty officers are now routinely prefacing their greetings with "Sorry you had to wait." One child who has been waiting with his father for three hours is given a form for the $x$ ray department within seconds of being seen. His father mutters predictable things as they leave. Two elderly women sit down. It is 20 minutes before one of them plucks up enough courage to ask how her husband is. The student nurse disappears into emergency and comes back. "Yes, he's had a heart attack," she confirms, and yes they can see him now. Before she escorts them in she warns them that how he looks may come as a bit of a shock: he's not very well really, he's on a monitor, and has this drip up. Then, he's alive! The old woman's eyes blaze. I have seen love.

Three hours later there are no familiar faces in the waiting area and the waiting time is down to 20 minutes. There seem to be many people limping - people who have managed all day who are coming in after work. And there are those who have come from their general practitioners for second opinions. "I've never known an infection to go away by itself," announces a man to nobody in particular about why he has brought his child in.

The first drunk of the day makes a stunning entrance from his cubicle-naked except for a blue hospital dressing gown, untied at the waist. He is the first of many; from now until morning alcohol is on the breath of every second or third person who comes in. Thursday is when giros are cashed and nightclubbing starts.

A policeman arrives and recognises a man sitting next to me who has bruises on his face and blood on his shirt. The policeman seems to belong to that other world that exists only in Kilroy and Falcon Crest. He is well groomed and fit, and has a very deep sun tan for late November. He sits between us and takes the man's statement.

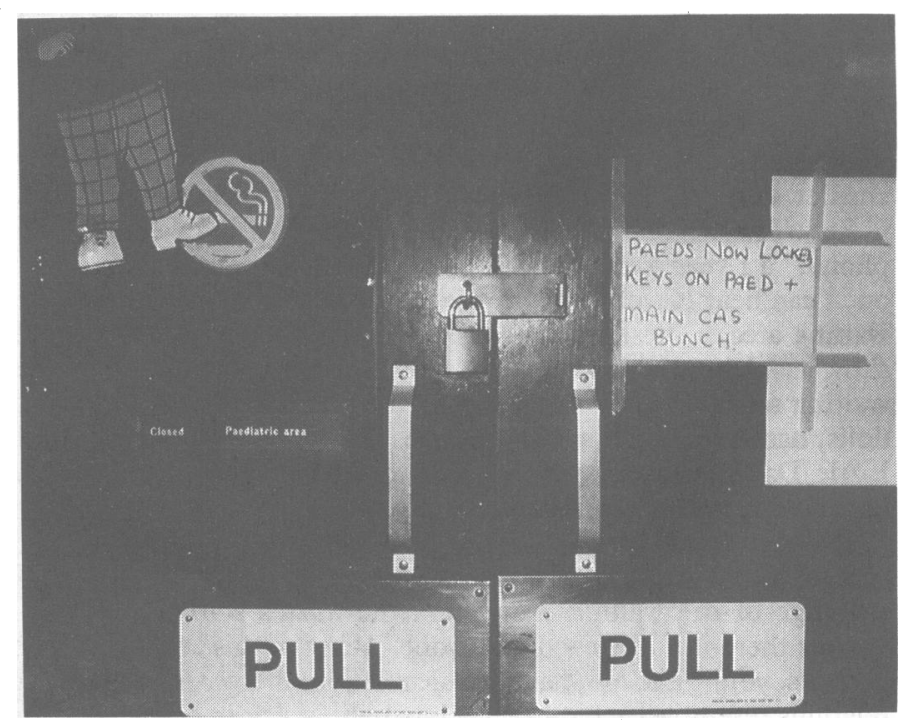

"Outside the children's area would have been the right place to sit six months ago. The children's area ensured that children could be dealt with immediately and kept away from older patients-a separation benefiting both sides. But shortages of nurses and doctors mean that it is now open only occasionally." 
"And he said I really deserve an apology from you. And I said well I'll go into all the details and if I find we owe you an apology then we'll give you an apology. And he said no, I want it now. And if you aren't prepared to give it to me, then ... I'm going to do you. And then. ..." And then this man of 50 starts to sob and tears run down his cheeks, and the policeman comforts him. "Take your time," he says gently. When the man recovers his composure the policeman carefully explains his legal position to him.

Out from seeing the doctor comes a mother carrying a baby. She is followed by a boy of about 4 or 5 carrying an enormous bag in one hand and the bottle of medicine prescribed for his baby brother in the other. He tries to lift the bag up on to a chair, but the bag is too big and he is too small, and anyway he is carrying the bottle of medicine in his other hand. He makes one last almighty effort to lift the bag on to the chair but only succeeds in sending the chair crashing into the row behind.

"You behave yourself," his mother shouts. "You running amok in this hospital? You wait until I get you home, son." He brushes this off with a weary sigh. He has seen this and so much else before, already. At this particular moment he knows he is coping better than his mother. Just.

More alcohol, this time taken with a handful of paracetamol by a girl who is still wandering around the department at midnight. Her parents and boyfriend try unsuccessfully to shepherd her for the long time between her stomach wash out and when the biochemistry department telephones down her four hour blood concentrations. Another drunken man sitting by the triage desk thinks he can speed up the process. "Nurse," he calls out, "do I call you murse or sister?" Then he rolls up his trouser leg and unwinds the filthy bandage around his leg. ("Sit down, my love, we're busy.")

If it's Hogarth inside then out in the corridor it's Blake. And the hapless Soldier's sigh, Runs in blood. . . . I have to check that wall again. Is the blood still smeared there? Is it really blood, or maybe just graffiti in red felt pen, inadequately cleaned? Would Blake think they were the same thing?

On my way there I pass a child sitting outside the locked children's area, barefoot, with a gash on his foot bleeding on to the floor. He holds a swab, mesmerised by the large red circle. He has obviously been left by his mother, who has gone to look for help, and he should have been holding the swab against the gash but that is difficult when you are 2 years old.

"All right mate, fuckin' bleed to death before I see you," she bellows down the corridor. Further down the corridor her 4 year old is attacking the Coke machine as if it were a one armed bandit and he a gambler who had lost his fortune. After three hours the cut is finally sorted out. Apparently the mother had left a 3 week old baby at home, whom she was breastfeeding; the porter to whom I spoke thought she was coping "fairly well."

Outside the children's area would have been the right place to sit six months ago. The children's area ensured that children could be dealt with immediately and kept away from older patients-a separation benefiting both sides. But shortages of nurses and doctors mean that it is now open only occasionally. Across from the children's area are the stairs and lift to the observation ward, which is closed as often as the children's area and for the same reason. Parts for the 80 year old lift are no longer available from its manufacturer, and anyway its open wire cage design is no longer permitted by the Health and Safety Executive. But the lift is still pressed into action whenever there are enough nurses to staff the observation ward. Halfway down the stairs from the ward is a window surrounded by ulcers and running sores.

Just before $10 \mathrm{pm}$ the administrator rings up the department to find out what the hospital bed state is. The senior registrar who has been working there since early morning takes the call. Administrators have rarely shown quite that much interest, but three days earlier somebody had waited from half past midnight

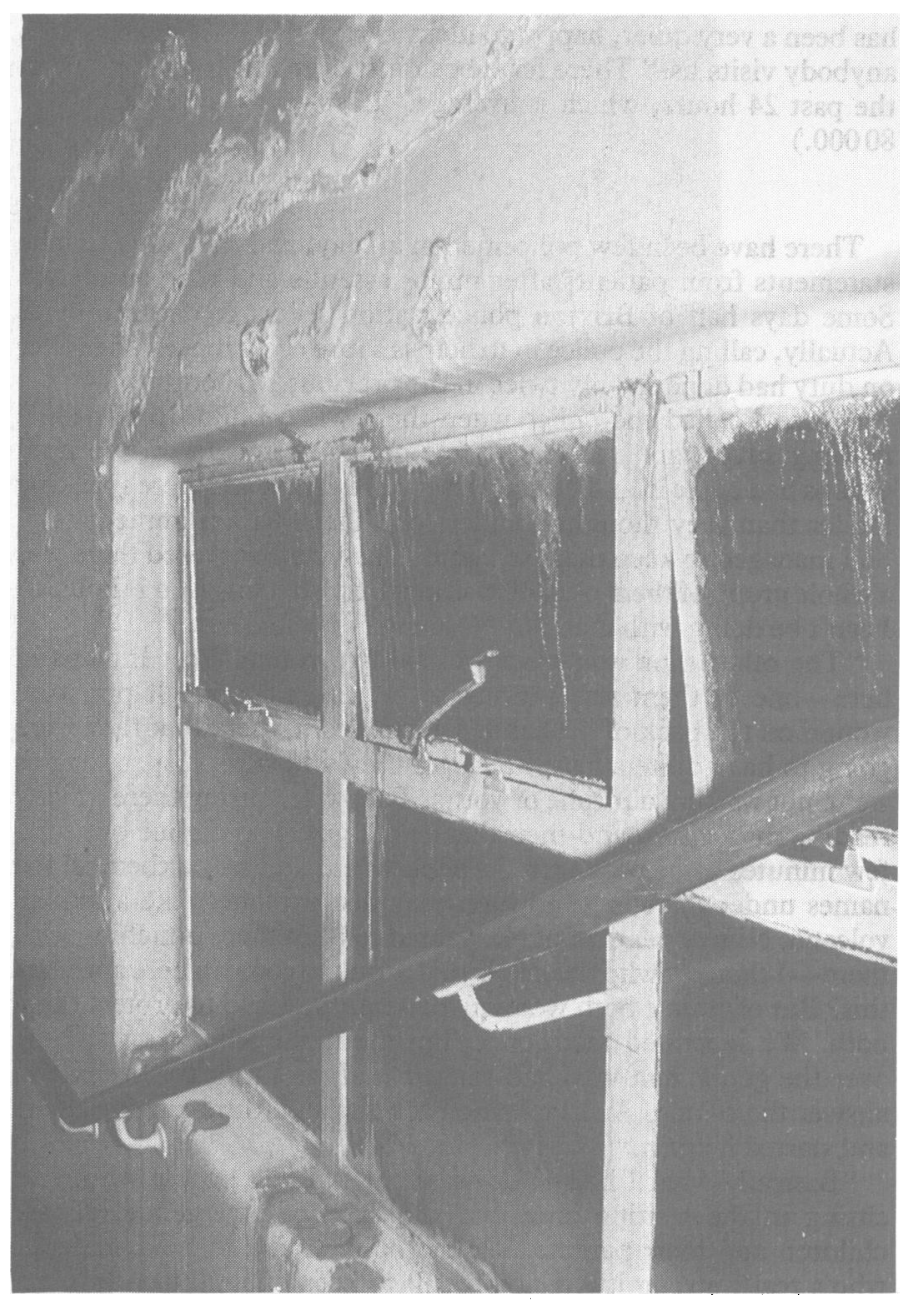

"Halfway down the stairs from the ward is a window surrounded by ulcers and running sores."

until 230 the following afternoon for a bed, and the administrators had caught a certain amount of flak. Usually the bed state is available by $10 \mathrm{pm}$, but as the department that prepares it has only two members of staff instead of its complement of seven it arrived a little late.

$1020 \mathrm{pm}$ and somebody is booking in his friend who has been punched in the ribs and cannot stand too well.

"Date of birth?" he is asked.

"Good question," his friend chirrups. "He's 14."

A few drunken verses of rebel songs come from the bench just outside reception. One man only "came up for the walk" with his friend, but now he decides he'll get his leg ulcer of long standing seen to. He is told by sister that he will be seen (nobody who wants to see a doctor is turned away), but she reminds him of the proper function of an accident and emergency department. He tells her to poke it up her arse.

I wonder if all these Thursday night drunks are single men living in hostels, but it turns out that most of them are married. "We see their other halves when they get home and beat them up," I was assured. And sure enough the next ambulance brings in proof.

"Why don't you leave him?" they ask their bleeding patient on the way in.

"Because he's such a good man when he's sober," she replies. And besides, she has a 7 year old child.

"But he may start on him," they tell her,

The ambulanceman runs his finger down the registration book to see if he has missed any excitement that night. "What a load of crap, eh?" It is true, not a lot has happened today. No serious road accidents, no shootings, not even any stabbings (down since the amnesty for knives, the receptionist thinks). According to sister it 
has been a very quiet, happy go lucky sort of day. "Always is when anybody visits us." There have been just over 200 consultations in the past 24 hours, which is average. (Last year's total figure was 80000.)

There have been few policemen in all day, and then only to take statements from patients after minor assaults and road accidents. Some days half of Brixton police station seems to decamp here. Actually, calling the police in to help is a rare occurrence. The sister on duty had done so only twice in the previous 18 months.

"Once I called the police when there was a build up of people flashing silverware outside. A few of the members of two rival groups had come in and because they were drunk and were speaking louder than they thought I understood the situation immediately. So I managed to keep them separate. Then we discovered there was a whole group of them outside waiting to finish it off. And I thought, I can't be doing with that."

"The other time was when we had five young West Indians in here-one of them was waiting to be seen for a small puncture wound on the back of his hand. I explained to them that they were going to have quite a long wait, and they said sure, just so long as we're not wasting our time or yours. They were sitting there quietly reading magazines, and then this drunk guy who'd gone out for a few minutes came back into the department and called them all the names under the sun. And then they just exploded like a human volcano. Ninety per cent of me wanted to be in there punching with them-I thought who the hell is this drunk to come in here and start this? But of course both were my patients, so I had to protect them both. We separated them once, but the nurse who was watching over the gentleman who had started it all had to leave his side to answer the phone. And he came back through the swinging doors and started it again.

"Basically what I had to do was to get all the people who were sitting in the waiting area into the back of emergency, all the children and their parents. When you're trying to hold someone who's really strong it's very difficult to keep enough breath to say 'Look I don't agree with what he said any more than you do, but I can't have this sort of behaviour going on in my department.' I received quite a strong blow to the stomach; because they were throwing punches the only way I could stop it was to put myself between them and the Irishman who had come in shouting all the abuse. So that night we called the police. In actual fact we had managed to get it under control by the time they arrived. They're pretty good, they respond quickly. But you can imagine from the area we're in they've got their work cut out already."

She regretted the effects these sporadic outbreaks of violence have on those waiting to be seen, but what she found more demoralising was the lack of space, staff, and equipment, which was constant.

"It's a lovely hospital to work at for the atmosphere, but it's no fun trying to work here when it's really, really busy. You've just got nowhere to put anyone. You can't move. You try and keep everyone informed of what's going on, but obviously you can't give them a breakdown of each individual patient. Doctors continue to accept patients when there isn't anywhere to put them. Not only do you have a build up of people taking up space down here, but you've also got to look after them while they're here, and we just haven't got the staff. I don't think anybody finds it more unpleasant than the patient waiting to be admitted. It wears the staff down after a while, too. It's absolutely ridiculous. You can't explain to a member of the public that you are a hospital without beds. It sounds like you're trying to fob them off, which really does make them angry. And I think rightly, as well."

It is $\mathbf{4}$ am, and except for a drunk and a locum casualty officer watching Beneath the Planet of the Apes the waiting area is empty. For the first time in almost 24 hours so are all six cubicles. The nurses throw themselves into cleaning them top to bottom (there are no domestic staff between $6 \mathrm{pm}$ and $7 \mathrm{am}$ ). They stretch to clean the walls above the unofficial limits agreed with the domestics; they replenish stocks and check all the supplies in emergency. They run through the procedures for major accidents. Then they stop for a slice of chocolate cake. I leave to catch the first bus home. The drunk whom they have been halfheartedly trying to get rid of for the last few hours thinks that a bus ride is a great idea and starts to follow me to the bus stop. From nowhere materialises a security officer, who keeps him talking long enough for me to make my getaway.

A visit to the accident and emergency department of King's College Hospital shows you care. The Secretary of State for Social Services and the chief executive of the National Health Service Management Board have both been recent visitors. It is this year's version of a trip to down town Liverpool. Michael Heseltine rather spoilt that number, though, by being moved by what he sawhardly the point at all. Besides, Liverpool is so far away, and the natives cannot be relied on to be friendly. Here people take their anger and frustration out on each other, or themselves.

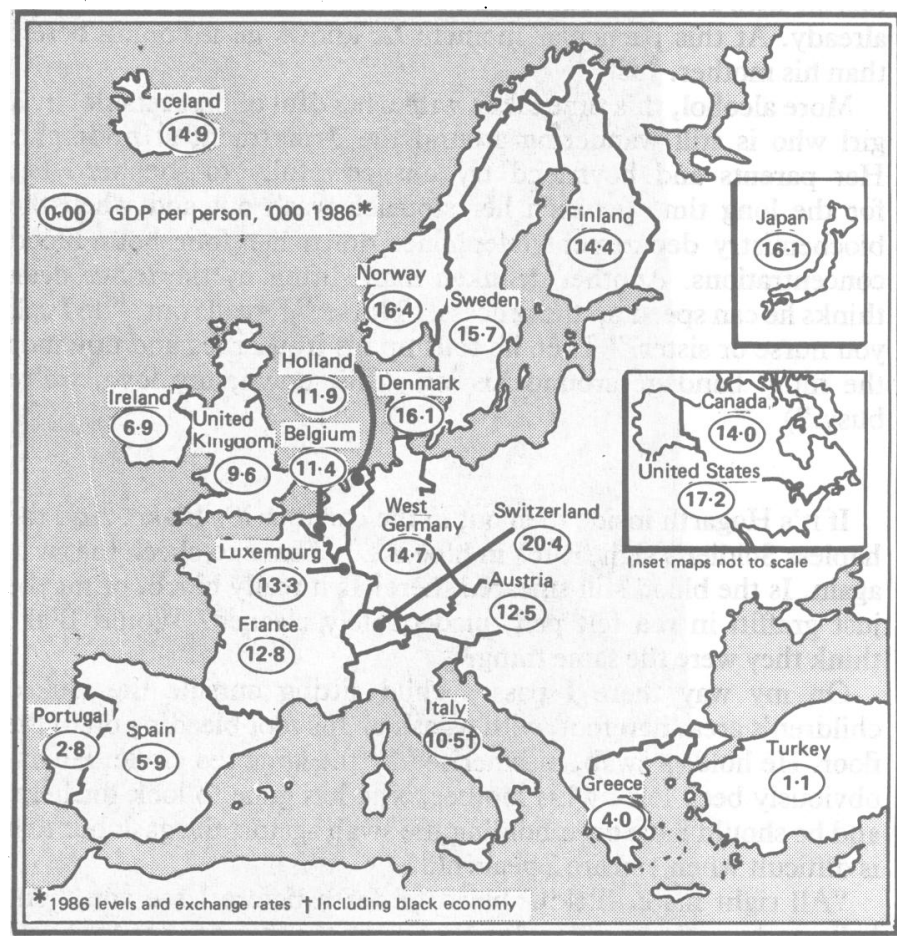

One reason why-and why our health service, prisons, research, education, and environment are unlikely to improve compared with other Western countries. Gross domestic product per person (courtesy of The Economist).

I spent nearly 24 hours trying to read the signs at King's and I still haven't decided what they mean. There are too many of them: no clear message emerges. Perhaps if I had spent less time there things would have seemed more clear cut. Let us just say that you can find support there for any beliefs you may have about the health service.

It is easier to tell you what it wăsn't. It wasn't "crisis management" despite the shortage of cubicles, trolleys, chairs, doctors, nurses, cleaners, porters, and other ancillary staff. Members of staff never lost their cool, their politeness, their compassion. After three hours' waiting some people vented their anger on the first person they saw, invariably a nurse. The first thing they got was an apology, and then an explanation. Kind words turned away anger, again, and again, and again. Even at their busiest everybody still seemed to have a lot in reserve. Maybe it had been, as sister said, a happy go lucky sort of day.

I cannot justify to you why my local accident and emergency department should be better equipped than ones I have seen in the Third World, but I am surprised that its facilities are worse. My surprise is cheap and easy: I wonder what emotions the department 
engenders in those men and women who were sustained through the last war by the ideal of a future society free of want, disease, ignorance, squalor, and idleness. How do they respond when their first sight of a hospital is of two student nurses and a patient's relative struggling with two trolleys, a closed children's ward on one side, a condemned lift on the other, and between them and the $x$ ray department an obstacle course of buckets and basins carefully positioned under a leaking roof?

I cannot tell you that, and I cannot tell you from where the people who work there get their resources of politeness and humanity. And from what I saw I cannot tell you how long everyone is prepared to stick it.

British Medical Journal, London WC1H 9JR

TONY DELAMOTHE, MD, MRCP, assistant editor

\title{
Twenty steps towards a "closed society" on health
}

\author{
RICHARD SMITH
}

\begin{abstract}
Almost by definition it is difficult to obtain information on attempts by those in power to keep information secret and stop people talking publicly. Yet every day in our conversations with doctors, administrators, researchers, and others we hear stories of suppression of information about health and the health service. Our impression, and the impression of others, is that "there is a lot of it about"perhaps more than there was. Sir Douglas Black discusses the "closed society" in a leading article (p 1582). I have compiled a list of examples to illustrate his theme and give some idea of the scale of the suppression. By its nature the list is idiosyncratic, far from complete, and may even be inaccurate in places, although it has been checked wherever possible. Written evidence is available to support many of the cases.
\end{abstract}

1. The wording of the contract of researchers funded by the Department of Health and Social Security has been changed in a way that most researchers interpret as an attempt to inhibit publication of results that may not support government policy. Previously the wording was: "any comments which the Secretary of State makes [on proposed publications] shall be considered by the researcher but the researcher shall nevertheless be able to allow publication to go forward in the original form as he thinks fit"; now the contract specifies that publication "is subject to the prior consent of the Secretary of State, which consent shall not be unreasonably withheld."

Researchers are worried not only about suppression but also that the credibility of their research may be undermined-how can the reader know whether important information has been suppressed? The possibility arises that editors of journals may decline to publish papers that may or may not have been censored, or they may demand to know whether anything has been changed. They may then wish to tell their readers that the article has been changed and to indicate where.

Researchers are also worried about delay. At the moment if the researchers do not hear back from the DHSS in 28 days they simply proceed to publication. If they must have a clear indication they may have to wait months-perhaps until long after the time when their work would have been important (or controversial).

2. Nicholas Ridley, Secretary of State for the Environment, was reported by Dr Michael O'Donnell in the Guardian (24 June, p 13) to have written to Tony Newton, Minister of Health, to ask him to "silence" Mr John Guy, an orthopaedic surgeon at the Worcester Royal Infirmary. Mr Guy had written to the people on his waiting list to say that financial cuts in the health authority meant that they could not have their hip replacement operations. He suggested that they write to their members of parliament. One patient sent a copy of Mr Guy's letter to Mr Ridley, who responded by writing to $\mathrm{Mr}$ Newton, saying "It seems to me intolerable that employees of the Health Service should openly criticise their health authorities in this sort of way."

A question was asked about the letter in the House of Lords (13 July), but the government declined to comment.

3. The attempt by Sir Brian Bailey, chairman of the Health Education Council, to block publication of the council's report on poverty and health has been extensively described in the $B M F$ and elsewhere. (As a postscript to this episode, an applicant for a job at the new Health Education Authority was asked in his interview what he would do to "shut up" critics of the authority.)

4. When Mr Victor Paige resigned as chairman of the NHS Management Board the West Midlands Regional Health Authority sent a telex to its 22 districts telling them not to comment on the matter. The regional authority said that it had received a call from the DHSS instructing them not to comment. (Reported in The Times, 5 June 1986, p 1.)

5. Mr Jeff Prosser, unit general manager of community and priority services in Tower Hamlets Health Authority, wrote to all his staff on 2 November 1987 to tell them that they are "not permitted to make contacts ... with members of parliament, newspapers, local councillors, and health authority members." He did so because of an "incident which caused the authority some embarrassment" and said that "a breach of these instructions could result in disciplinary proceedings." (I have a copy of this letter.)

6. Sir Bryan Thwaithes, chairman of Wessex Regional Health Authority, was asked (told) by the government to keep quiet after he had spoken during the election of the impossibility of NHS funds keeping up with the expectations of patients and doctors.

7. The chairmen of the London district health authorities were pressurised by the NHS Management Board not to publish their report on back to back health planning in London, which highlighted severe deficiencies in the acute hospitals in London. They published it anyway.

8. North West Hertfordshire Health Authority has three times disciplined Mr Doug Landman, St Albans branch secretary of the Confederation of Health Service Employees, for speaking to the press on conditions in Hill End Hospital.

9. Politically sensitive figures produced by the Department of Health and Social Security are often published late on Friday afternoons and placed in the House of Commons Library. The DHSS press office has only a limited version of the figures, which 